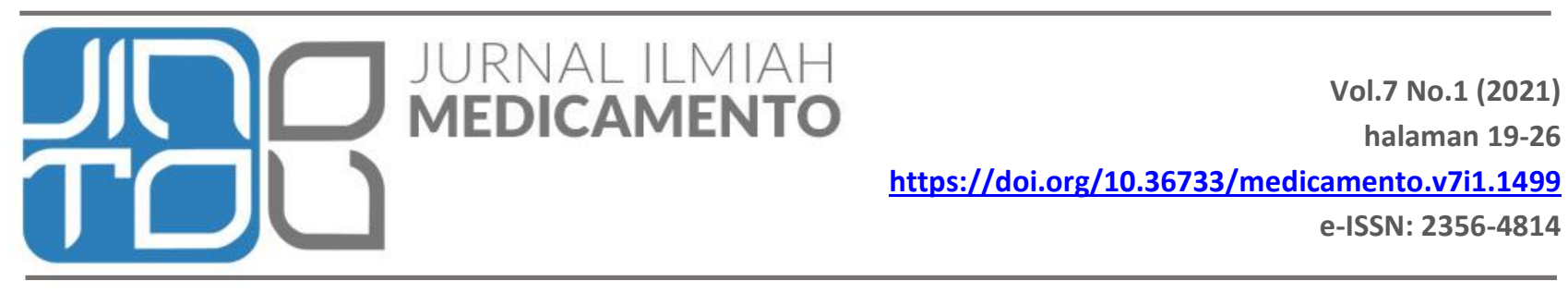

\title{
Hubungan Dukungan Keluarga dan Peran Tenaga Kefarmasian terhadap Kepatuhan Minum Obat Antihipertensi
}

\section{Relationship Between Family Support and Pharmacist Role with Adherence Hypertension Therapy}

\author{
Dewi Puspita Apsari ${ }^{10}$, I Gusti Ngurah Manik Satria Wibawa Putra ${ }^{1}$, I.B.N. Maharjana ${ }^{1}$ \\ ${ }^{1}$ Program Studi Farmasi Klinis, Fakultas IImu-IImu Kesehatan, Universitas Bali Internasional, Denpasar, Bali, Indonesia
}

\begin{abstract}
Abstrak: Hipertensi yang tidak terkontrol dapat mengakibatkan berbagai macam komplikasi. Ketidakpatuhan terhadap pengobatan adalah salah satu penyebab hipertensi tidak terkontrol. Dukungan keluarga dan peran tenaga kefarmasian yang tinggi merupakan faktor yang dapat mempengaruhi kepatuhan pasien dalam menjalankan terapi hipertensi. Penelitian ini bertujuan mengetahui hubungan dukungan keluarga dan peran tenaga kefarmasian terhadap kepatuhan minum obat antihipertensi di Puskesmas. Desain penelitian yang digunakan adalah analitik dengan pendekatan cross sectional study. Penelitian dilaksanakan pada bulan Maret-Mei tahun 2020 dan populasi pada penelitian ini adalah 100 pasien hipertensi lansia yang melakukan pengobatan rawat jalan di Puskesmas Mengwi I. Kuisioner digunakan untuk menilai tingkat kepatuhan, dukungan keluarga dan peran tenaga kefarmasian. Analisis data dilakukan dengan cara univariat dan bivariat dengan menggunakan uji Rank Spearman. Hasil uji statistik yang dilakukan didapatkan hubungan yang signifikan $(p=0,00)$ dan kuat $(r=0,558)$ antara skor total dukungan keluarga terhadap kepatuhan minum obat antihipertensi pada 73 (73\%) responden. Selain itu juga pada peran tenaga kefarmasian, terlihat hubungan yang signifikan $(p=0,00)$ antara penyediaan informasi, konseling pengobatan dan gaya komunikasi tenaga farmasi terhadap kepatuhan minum obat antihipertensi. Dari hasil penelitian dapat disimpulkan bahwa dukungan keluarga dan peran tenaga kefarmasian berpengaruh signifkan terhadap kepatuhan minum obat antihipertensi di Puskesmas Mengwi I.
\end{abstract}

Kata Kunci: dukungan keluarga, hipertensi, kepatuhan, peran tenaga kefarmasian.

\begin{abstract}
Uncontrolled hypertension can lead to various complications. Nonadherence to therapeutic plans has been reported for uncontrolled hypertension. Family support and pharmacist role are factors that can affect patient adherence in carrying out hypertension therapy. The purpose of this study was to determine the relationship between family support and pharmacist role with adherence therapeutic plans. The study was conducted in March-May 2020 and the population in this study were 100 hypertensive adult respondents who were undergoing outpatient treatment at Primary Health Care Mengwi I. The questionnaire was used to asess the level of adherence, family support and pharmacist role. Data analysis was performed by means of univariate and bivariate using Rank Spearman. Statistical test results found that there is a significant $(p=0,00)$ and strong $(r=0,558)$ relationship between total score family support with adherence hypertension therapy. In addtion, there is a significant $(p=0,00)$ between drug information, counseling, and communication styles of pharmacists with adherence hypertension therapy. From the research results, it can be concluded that family support and pharmacist role have an significant effect on adherence hypertension therapy in Primary Health Care Mengwi I.

Keywords: adherence, family support, hypertension, pharmacist role.
\end{abstract}

\section{PENDAHULUAN}

Hipertensi adalah kondisi yang kompleks dimana tekanan darah secara menetap berada di atas 140/90 mmHg (Mahajan, 2014). Hipertensi merupakan salah satu masalah yang cukup dominan di negara berkembang seperti Indonesia (Awaluddin dan Yuldeni, 2017). Berdasarkan hasil Riset Kesehatan Dasar tahun 2018, prevalensi hipertensi di Indonesia berkisar 34,1\%. Selain itu juga Provinsi Bali termasuk dalam salah satu

•email korespondensi: dewipuspitaapsari@gmail.com 
provinsi dengan kejadian hipertensi yang selalu mengalami peningkatan dari tahun ketahun. Provinsi Bali sendiri memiliki prevalensi hipertensi pada tahun 2018 sebesar 29,97\% (Kementerian Kesehatan RI, 2018). Hipertensi yang tidak terkontrol dapat mengakibatkan berbagai macam komplikasi diantanya penyakit jantung koroner, stroke, gagal jantung kongestif dan insufisiensi ginjal. Keseluruhan penyakit tersebut merupakan penyebab morbiditas dan mortalitas terbesar dari penyakit hipertensi (Zhang et al., 2011).

Ketidakpatuhan terhadap pengobatan adalah salah satu penyebab hipertensi tidak terkontrol (Faselis et al., 2011). Hasil penelitian yang dilakukan tahun 2019 di Cina mengatakan bahwa kepatuhan pengobatan hipertensi sebesar 27,46\% (Pan et al., 2019), sedangkan di Indonesia sebesar 59\% (Tania dkk., 2019). Kepatuhan dianggap penting dikarenakan hipertensi merupakan penyakit yang tidak dapat disembuhkan tetapi harus selalu dikontrol dengan menjalankan pengobatan secara teratur seumur hidup (Ariyani dan Hartanto, 2018). Terdapat beberapa cara untuk mengukur tingkat kepatuhan pasien dalam menjalani pengobatan, salah satunya dapat diukur menggunakan metode kuesioner Morisky Medication Adherence Scale (MMAS-8) (Morisk et al., , 2008). Kuesioner ini telah divalidasi untuk digunakan di beberapa negara dengan beberapa golongan pasien (Plakas et al., 2016). Selain itu juga memiliki nilai sensitivitas (93\%), spesifisitas (53\%) dan Cronbach"s $\alpha=0,83$ (Tan et al., 2014)

Terdapat banyak faktor yang
mempengaruhi kepatuhan pasien dalam menggunakan obat antihipertensi, salah satunya adalah dukungan keluarga. (Tumenggung, 2013). Dukungan keluarga penting dalam manajemen jangka panjang hipertensi. Penelitian yang dilakukan Ojo et al., (2016) didapatkan bahwa sebesar $286(79,4 \%)$ pasien hipertensi menyatakan dukungan keluarga yang kuat dapat meningkatkan kepatuhan minum obat hipertensi. Dukungan keluarga yang kuat akan meningkatkan harga diri dan motivasi pasien, sehingga sangat masuk akal bahwa pasien hipertensi termotivasi mematuhi rencana terapi (Ojo et al., 2016). Selain itu juga dukungan keluarga dapat menolong pasien dalam pemilihan obat yang benar, serta peran keluarga dapat memberi akses dalam pengelolaan kesehatan sehingga didapatkan hasil yang lebih baik dalam menangani penyakit hipertensi (Shen et al., 2017).

Faktor lainnya yang juga memberikan pengaruh yang signifikan dalam melaksanakan kepatuhan dalam minum obat hipertensi adalah peran dari tenaga kesehatan, khususnya tenaga kefarmasian. Menurut PP 51 tahun 2009, yang berhak melaksanakan penyerahan dan pelayanan obat berdasarkan resep dari dokter adalah Apoteker. Apoteker berperan dalam pemberian edukasi dan konseling terutama untuk pasien penyakit kronis sehingga dapat meningkatkan kepatuhan dalam pengobatan dan keberhasilan terapi (Avalere Health, 2014). Kenyataannya, jumlah apoteker pada Puskesmas justru terbilang sangat sedikit. Dari jumlah total 9.655 Puskesmas di Indonesia, total apoteker di Puskesmas keseluruhan hanya sejumlah 1.539 orang. Beberapa Puskesmas ada yang memiliki apoteker, sisanya hanya memiliki tenaga teknis kefarmasian, bahkan terdapat Puskesmas yang sama sekali tidak memiliki keduanya (Pusat Data dan Informasi, 2018). Penelitian yang dilakukan Pratiwi tahun 2017 menunjukkan bahwa terdapat hubungan yang signifikan yakni jika peran petugas kefarmasian yang tinggi akan mengakibatkan 66,1\% penderita hipertensi patuh terhadap pengobatannya (Pratiwi, 2017). Melihat permasalahan di atas, perlu dilakukan penelitian untuk mencari hubungan dukungan keluarga dan peran tenaga kefarmasian terhadap kepatuhan minum obat antihipertensi di Puskesmas.

\section{METODE PENELITIAN}

Penelitian ini merupakan penelitian analitik dengan desain cross sectional study. Penelitian ini telah memperoleh ijin kelaikan kode etik dari Komisi Etik Penelitian (KEP) Fakultas Kedokteran Universitas Udayana dengan Nomor: 1332 /UN14.2.2VII.14 /LT/2020. Pengambilan data dilakukan pada bulan Maret-Mei tahun 2020. 
Populasi pada penelitian ini adalah pasien hipertensi lansia yang melakukan pengobatan rawat jalan di Puskesmas Mengwi I. Rumus slovin digunakan dalam perhitungan sampel, sehingga didapatkan jumlah 100 sampel yang perlu diteliti. Jumlah sampel tersebut memiliki power $90 \%$ dan $\alpha$ $=0,05$. Teknik pengambilan sampel dilakukan secara purposive sampling.

Pengukuran kepatuhan dilakukan dengan menggunakan kuesioner MMAS-8 yang terdiri dari 8 pertanyaan. Kuesioner yang digunakan sudah diterjemahkan ke bahasa Indonesia berdasarkan penelitian yang dilakukan oleh Arisuwita tahun 2016. Penilaian kepatuhan dilakukan dengan jalan menjumlahkan setiap skor jawaban partisipan. Kuesioner yang digunakan telah diuji validitas dan reliabilitasnya dengan nilai validitas >0,361 dan reliabilitas 0,777 . Partisipan memiliki tingkat kepatuhan minum obat yang rendah, sedang dan tinggi jika mendapatkan skor total $<6,6$ atau 7 dan 8 secara berturut-turut.

Pengukuran dukungan keluarga dilakukan dengan menggunakan kuesioner yang diadaptasi dari penelitian Indriyanto tahun 2015. Karakteristik subjek penelitian yang digunakan pada penelitian sebelumnya sama dengan penelitian ini. Kuesioner yang digunakan terdiri atas 3 domain yakni 4 pernyataan terkait dukungan emosional dan penghargaan, 4 pernyataan terkait dukungan instrumental dan 4 pernyataan terkait dukungan informasi. Kuesioner yang diberikan berupa pernyataan pilihan dalam bentuk checklist. Responden hanya mengisi dan menandai jawaban yang dianggap sesuai dan tepat. Instrumen kuisoner ini menggunakan sistem scoring Skala Likert. Dari setiap pernyataan tersebut dirancang dengan jawaban yaitu skala $4=$ selalu, skala $3=$ sering, skala 2=kadang-kadang dan skala 1=tidak pernah. Kuesioner yang digunakan telah diuji validitas dan reliabilitasnya sesuai dengan dengan nilai validitas $>0,361$ dan reliabilitas 0,774. Partisipan memiliki dukungan keluarga yang rendah jika skor total partisipan 0-50\% dan dukungan keluarga yang tinggi jika skor total partisipan 51-100\%.
Pengukuran peran tenaga kefarmasian menggunakan kuesioner yang diadaptasi dari penelitian Koster et al., tahun 2016. Karakteristik subjek penelitian yang digunakan pada penelitian sebelumnya adalah bukan pasien hipertensi melainkan pasien umum yang mengunjungi farmasi. Kuesioner yang digunakan terdiri atas 3 domain yakni 3 pernyataan terkait penyediaan informasi, 4 pernyataan konseling pengobatan dan 3 pernyataan terkait dukungan gaya komunikasi tenaga farmasi. Kuesioner yang diberikan berupa pernyataan pilihan dalam bentuk checklist. Responden hanya mengisi dan menandai jawaban yang dianggap sesuai dan tepat. Instrumen kuisoner ini menggunakan sistem scoring Skala Likert. Dari setiap pernyataan tersebut dirancang dengan jawaban yaitu skala $4=$ selalu, skala $3=$ sering, skala $2=$ kadang-kadang dan skala $1=$ tidak pernah. Kuesioner yang digunakan telah diuji validitas dan reliabilitasnya sesuai dengan dengan nilai validitas $>0,361$ dan reliabilitas 0,786 . Partisipan memiliki peran tenaga kefarmasian yang rendah jika skor total partisipan 0-50\% dan peran tenaga kefarmasian yang tinggi jika skor total partisipan 51-100\%.

Analisis data yang dilakukan dengan cara univariat untuk mengetahui distribusi frekuensi variabel-variabel yang diteliti dapat berupa tabel distribusi frekuensi. Analisis bivariat dilakukan untuk melihat hubungan dukungan keluarga dan peran tenaga kefarmasian terhadap kepatuhan terapi hipertensi di Puskesmas Mengwi I. Uji statistik yang digunakan adalah uji Rank Spearman dengan derajat kemaknaan signifikan $(\alpha)$ 0,05 dan kepercayaan 95\%. Untuk melihat kekuatan hubungan ( $r$ ) antar variabel maka dapat dikategorikan sebagai berikut: 0,00-0,25 berarti hubungan sangat lemah, 0,26-0,50 berarti hubungan cukup, 0,51-0,75 berarti hubungan kuat, 0,76-0,99 berarti hubungan sangat kuat dan 1,00 berarti hubungan sempurna (Sarwono, 2012).

\section{HASIL DAN PEMBAHASAN}

Karakteristik responden yang diikutkan dalam penelitian dapat dilihat sesuai dengan tabel 
1. Mayoritas 100 responden yang diteliti berusia 60-74 tahun sebesar 86 (86\%), berjenis kelamin perempuan 55 (55\%), memiliki tingkat pendidikan terakhir SD 29 (29\%) dan sudah tidak bekerja sebesar 65 (65\%).

Data pada tabel 2 menunjukkan bahwa terdapat hubungan yang kuat $(r=0,558)$ dan signifikan $(p=0,00)$ antara skor total dukungan keluarga terhadap kepatuhan minum obat antihipertensi pada 73 (73\%) responden. Hal ini menunjukkan semakin tinggi dukungan keluarga, semakin patuh pasien untuk meminum obat antiipertensi. Hasil penelitian yang didapat sejalan dengan penelitian yang dilakukan oleh Ojo et al., (2016) yakni 79,4\% responden menyatakan dukungan keluarga yang tinggi dapat meningkatkan kepatuhan minum obat hipertensi. Dukungan keluarga sangat penting dalam pengobatan hipertensi jangka panjang.

Tabel 1. Karakteristik Respon Penelitian

\begin{tabular}{lcc}
\hline Karakteristik Responden & Frekuensi & $\%$ \\
\hline Usia & 0 & 0 \\
$45-59$ tahun & 86 & 86 \\
60-74 tahun & 14 & 14 \\
$75-90$ tahun & 0 & 0 \\
$>90$ tahun & & \\
Jenis Kelamin & 45 & 45 \\
Laki-laki & 55 & 55 \\
Perempuan & & \\
Pendidikan Terakhir & 11 & 11 \\
Tidak sekolah & 29 & 29 \\
SD & 25 & 25 \\
SMP & 25 & 25 \\
SMA/SMK & 10 & 10 \\
Diploma/S1 & & \\
Pekerjaan & 35 & 35 \\
Bekerja & 65 & 65 \\
Tidak bekerja & & \\
\hline
\end{tabular}

Pasien lansia penderita hipertensi membutuhkan orang terdekat yang tinggal serumah untuk memberikan dukungan kepada pasien agar tetap merasa dicintai dan semangat dalam menjalani pengobatan (Friedman et al., , 2010). Namun dilapangan masih ada beberapa responden lansia yang datang ke Puskesmas sendiri tanpa didampingi oleh keluarganya karena sedang bekerja, namun itu tidak menjadi suatu masalah bagi responden karena keluarga tetap memberikan dukungannya dirumah sehingga pasien merasa dicintai dan tetap semangat menjalani pengobatan.

Pada tabel 2 terlihat dukungan yang diberikan keluarga terbagi atas dukungan emosional dan penghargaan, dukungan instrumental, dan dukungan informasi. Pada penelitian ini terlihat terdapat hubungan yang signifikan $(p=0,00)$ antara dukungan emosional dan penghargaan, dukungan instrumental, dan dukungan informasi terhadap kepatuhan minum obat antihipertensi pada 73 (73\%) responden. Dukungan emosional dan penghargaan membantu pasien hipertensi agar menjalani kehidupannya dengan baik. Pasien hipertensi membutuhkan kemauan untuk memandang hidup sebagai sebuah harapan dan juga dibutuhkan pikiran yang positif dalam memandang setiap permasalahan yang mereka alami (Setiadi, 2008).

Dukungan instrumental yang perlu diberikan kepada pasien hipertensi berupa perlengkapan, peralatan dan sarana pendukung lain. Adanya dukungan instrumental akan mengakibatkan pasien teratur menjalani terapi, kebutuhan makan, minum dan istirahat terpenuhi dan terhindarnya penderita dari kelelahan. Dukungan informasi adalah berupa pemberian nasehat, saran, petunjuk atau pengarahan terkait penyakit hipertensi (Friedman et al., 2010). Berdasarkan data dalam kuesioner dukungan informasi didapatkan paling banyak keluarga selalu mengingatkan pasien tentang perilaku-perilaku buruk yang dapat memperburuk keadaan penyakitnya, selalu mengingatkan untuk kontrol, minum obat, olahraga dan makan serta selalu memberitahu tentang hasil dari pemeriksaan kesehatan pasien itu sendiri.

Peran tenaga kefarmasian terhadap kepatuhan minum obat terbagi atas penyediaan informasi, konseling pengobatan dan gaya komunikasi tenaga farmasi sesuai dengan tabel 3. Pada tabel 3 terlihat, sebagian besar pasien memiliki tingkat kepatuhan minum obat yang tinggi karena peran tenaga kefarmasian yang tinggi. Hasil penelitian ini sejalan dengan penelitian yang dilakukan oleh Pratiwi tahun 2017 yang 
menunjukan terdapat hubungan signifikan antara peran tenaga kefarmasian dengan perilaku lansia dalam pengendalian hipertensi.

Pada penelitian ini terlihat hubungan yang signifikan $(p=0,00)$ dan kuat $(r=0,597)$ antara penyediaan informasi terhadap kepatuhan minum obat antihipertensi pada 72 (72\%) responden. Penyediaan informasi merupakan faktor yang paling tinggi diantara dua faktor lainnya pada peran tenaga kefarmasian. Hasil yang didapat sesuai dengan penelitian yang dilakukan di Kupang yakni terdapat hubungan signifikan $(p=0,031)$ antara pelayanan informasi obat dengan tingkat kepatuhan pasien hipertensi di Puskesmas Beru Kabupaten Sikka. Penyediaan informasi terkait obat dapat meningkatkan pengetahuan pasien dalam penggunaan obat yang tepat dan memotivasi pasien untuk menggunakan obat sesuai dengan anjuran penggunaan yang telah diberikan (Pare, 2020).

Tabel 2. Hubungan Dukungan Keluarga terhadap Kepatuhan Minum Obat

\begin{tabular}{cccccc}
\hline $\begin{array}{c}\text { Domain Dukungan } \\
\text { Keluarga }\end{array}$ & $\begin{array}{c}\text { Rendah } \\
\mathrm{n}(\%)\end{array}$ & $\begin{array}{c}\text { Sedang } \\
\mathrm{n}(\%)\end{array}$ & $\begin{array}{c}\text { Tinggi } \\
\mathrm{n}(\%)\end{array}$ & $\begin{array}{c}\text { Total } \\
\mathrm{n}(\%)\end{array}$ & $\begin{array}{c}\text { Hasil Uji } \\
\text { Statistik } \\
\text { Rank } \\
\text { Spearman }\end{array}$ \\
\cline { 2 - 4 } $\begin{array}{c}\text { Emosional dan } \\
\text { Penghargaan } \\
\text { Rendah }\end{array}$ & $2(2)$ & $8(8)$ & $4(4)$ & $14(14)$ & $\mathrm{p}=0,00$ \\
Tinggi & $1(1)$ & $12(12)$ & $73(73)$ & $86(86)$ & $\mathrm{r}=0,473$ \\
\hline $\begin{array}{c}\text { Instrumental } \\
\text { Rendah }\end{array}$ & $3(3)$ & $9(9)$ & $4(4)$ & $16(16)$ & $\mathrm{p}=0,00$ \\
Tinggi & $0(0)$ & $11(11)$ & $73(73)$ & $84(84)$ & $\mathrm{r}=0,558$ \\
\hline $\begin{array}{c}\text { Informasi } \\
\text { Rendah }\end{array}$ & $2(2)$ & $7(7)$ & $4(4)$ & $13(13)$ & $\mathrm{p}=0,00$ \\
$\quad$ Tinggi & $1(1)$ & $13(13)$ & $73(73)$ & $87(87)$ & $\mathrm{r}=0,436$ \\
\hline $\begin{array}{c}\text { Skor Total } \\
\text { Rendah }\end{array}$ & $3(3)$ & $9(9)$ & $4(4)$ & $16(16)$ & $\mathrm{p}=0,00$ \\
$\quad$ Tinggi & $0(0)$ & $11(11)$ & $73(73)$ & $84(84)$ & $\mathrm{r}=0,558$ \\
\hline
\end{tabular}

Tabel 3. Hubungan Peran Tenaga Kefarmasian terhadap Kepatuhan Minum Obat

\begin{tabular}{lccccc}
\hline \multirow{2}{*}{$\begin{array}{l}\text { Domain Peran } \\
\text { Tenaga Kefarmasian }\end{array}$} & $\begin{array}{c}\text { Rendah } \\
\mathrm{n}(\%)\end{array}$ & $\begin{array}{c}\text { Sedang } \\
\mathrm{n}(\%)\end{array}$ & $\begin{array}{c}\text { Tinggi } \\
\mathrm{n}(\%)\end{array}$ & $\begin{array}{c}\text { Total } \\
\mathrm{n}(\%)\end{array}$ & $\begin{array}{c}\text { Hasil Uji } \\
\text { Statistik } \\
\text { Rank } \\
\text { Spearman }\end{array}$ \\
\hline $\begin{array}{l}\text { Penyediaan } \\
\text { Informasi }\end{array}$ & & & & \\
$\begin{array}{l}\text { Rendah } \\
\text { Tinggi }\end{array}$ & $3(3)$ & $11(11)$ & $5(5)$ & $19(19)$ & $\mathrm{p}=0,00$ \\
\hline Konseling & $0(0)$ & $9(9)$ & $72(72)$ & $81(81)$ & $\mathrm{r}=0,597$ \\
$\begin{array}{l}\text { Pengobatan } \\
\text { Rendah }\end{array}$ & & & & & \\
Tinggi & $3(3)$ & $12(12)$ & $18(18)$ & $33(33)$ & $\mathrm{p}=0,00$ \\
\hline $\begin{array}{l}\text { Gaya Komunikasi } \\
\text { Tenaga Farmasi }\end{array}$ & $0(0)$ & $8(8)$ & $59(59)$ & $67(67)$ & $\mathrm{r}=0,385$ \\
$\begin{array}{l}\text { Rendah } \\
\text { Tinggi }\end{array}$ & $3(3)$ & $13(13)$ & $7(7)$ & $23(23)$ & $\mathrm{p}=0,00$ \\
\hline
\end{tabular}

Pada gaya komunikasi tenaga farmasi terdapat hubungan yang signifikan $(p=0,00)$ dan kuat $(r=0,614)$ antara gaya komunikasi tenaga farmasi terhadap kepatuhan minum obat 
antihipertensi pada 70 (70 \%) responden. Gaya komunikasi tenaga kefarmasian sangat dipengaruhi tingkat pengetahuan tenaga kefarmasian. Tingkat pengetahuan tenaga kefarmasian tentang pasien menentukan pemahaman tenaga kefarmasian tentang cara mendekati pasien, jumlah informasi yang perlu diberikan, dan kenyamanan tenaga kefarmasian dalam menghadapi pasien. Pengetahuan tenaga kefarmasian khususnya apoteker tentang kondisi dan pengobatan pasien yang dibicarakan dalam konseling juga penting karena apoteker harus mampu mengantisipasi isu-isu yang harus dibicarakan dan memberikan informasi yang diperlukan (Rantucci, 2007).

Pada peran tenaga kefarmasian dalam konseling pengobatan terdapat hubungan yang signifikan $(p=0,00)$ dan cukup $(r=0,385)$ antara konseling pengobatan terhadap kepatuhan minum obat antihipertensi pada 59 (59\%) responden. Kegiatan konseling merupakan salah satu cara untuk meningkatkan kepatuhan pasien. Saat konseling pasien diberikan informasi mengenai manfaat dan pentingnya pengobatan. Konseling obat kepada pasien diharapkan memberikan perubahan perilaku guna meningkatkan keberhasilan terapi pasien (Vlasnik et al.,2005).

\section{SIMPULAN}

Hasil penelitian menunjukkan bahwa terdapat hubungan yang signifikan $(p=0,00)$ antara dukungan keluarga dan peran tenaga kefarmasian terhadap kepatuhan minum obat antihipertensi di Puskesmas Mengwi I. Petugas kesehatan diharapkan dapat lebih meningkatkan lagi kualitas pelayanan kesehatan dengan memperbaiki metode, media maupun cara penyampaian konseling pengobatan. Selain itu juga tenaga kefarmasian hendaknya melakukan pendekatan kepada keluarga pasien sehingga keluarga lebih mudah untuk memberikan informasi mengenai penyakit pasien.

\section{UCAPAN TERIMA KASIH}

Terimakasih diucapkan kepada semua pihak yang telah membantu dan terlibat langsung dalam penelitian ini. Kepada semua civitas akademika Universitas Bali Internasional terima kasih telah memberikan sumbang saran, kritikan dan masukan agar sempurnanya penelitian ini. Peneliti juga menyampaikan ucapan terimakasih kepada Puskesmas Mengwi I yang telah memberikan izin untuk dapat melakukan pengambilan data penelitian.

\section{DAFTAR PUSTAKA}

Arisuwita, D. F. (2016). Hubungan Dukungan Keluarga dengan Perilaku Diet Pasien Diabetes Melitus di Wilayah Kerja Puskesmas Gamping 1 Sleman Yogyakarta. Retrieved from http://repository.umy.ac.id/handle/12345 $6789 / 2782$

Ariyani, H., \& HartantoDedi. (2018). Kepatuhan Pasien Hipertensi Setelah Pemberian Pill Card di RS X Banjarmasin (Adherence Of Hypertensive Patients After Giving Pill Card In Hospital X Banjarmasin). Journal Current Pharmceutical Science, 1(2), 81-88. Retrieved from https://www.researchgate.net/publicatio n/334478866_KEPATUHAN_PASIEN_HIPE RTENSI_SETELAH_PEMBERIAN_PILL_CARD _DI_RS_X_BANJARMASIN_Adherence_Of_ Hypertensive_Patients_After_Giving_Pill_ Card_In_Hospital_X_Banjarmasin

Avalere Health. (2014). Exploring Pharmacists' Role in a Changing Healthcare Environment, (May), 1-30.

Awaluddin, A., \& Yuldeni, Y. (2017). Hubungan Pengetahuan dan Shalat Terhadap Tekanan Darah pada Lansia. Jurnal Endurance, $1(3), \quad 144$. https://doi.org/10.22216/jen.v1i3.1533

Faselis, C., Doumas, M., \& Papademetriou, V. (2011). Common secondary causes of resistant hypertension and rational for treatment. International Journal of Hypertension.

https://doi.org/10.4061/2011/236239

Friedman, M. M., Bowden, V. R., \& Jones, E. G. (2010). Buku ajar Keperawatan Keluarga: 
Riset, Teori, dan Praktik (5th ed.). Jakarta: EGC.

Indriyanto, W. (2015). Hubungan Antara Dukungan Sosial Keluarga Dan Kepatuhan Lansia Hipertensi Untuk Kontrol Rutin Ke Posyandu Lansia Di Area Kerja Puskesmas Sugihwaras Bojonegoro. Retrieved from http://lib.unair.ac.id

Kementerian Kesehatan RI. (2018). Riset Kesehatan Dasar (Riskesdas). Badan Penelitian dan Pengembangan Kesehatan.

Koster, E. S., Blom, L., Overbeeke, M. R., Philbert, D., Vervloet, M., Koopman, L., \& van Dijk, L. (2016). Quality of pharmaceutical care at the pharmacy counter: Patients' experiences versus video observation. Patient Preference and Adherence, 10, 363-369.

https://doi.org/10.2147/PPA.S102032

Mahajan, R. (2014). Joint National Committee 8 report: How it differ from JNC 7 . International Journal of Applied and Basic Medical Research, 4(2), 61. https://doi.org/10.4103/2229-

516x.136773

Morisky, D. E., Ang, A., Krousel-Wood, M., \& Ward, H. J. (2008). Predictive validity of a medication adherence measure in an outpatient setting. Journal of Clinical Hypertension, 10(5), 348-354. https://doi.org/10.1111/j.1751-

7176.2008.07572.x

Ojo, O., Malomo, S., \& Sogunle, P. (2016). Blood pressure (BP) control and perceived family support in patients with essential hypertension seen at a primary care clinic in Western Nigeria. Journal of Family Medicine and Primary Care, 5(3), 569. https://doi.org/10.4103/2249-

4863.197284

Pan, J., Wu, L., Wang, H., Lei, T., Hu, B., Xue, X., \& $\mathrm{Li}, \quad \mathrm{Q}$. (2019). Determinants of hypertension treatment adherence among a Chinese population using the therapeutic adherence scale for hypertensive patients.
Medicine, 98(27), e16116. https://doi.org/10.1097/MD.0000000000 016116

Pare, M. H. (2020). The Relationship of Drug Information Services and Patient's Adherence in Hypertension Therapy in Beru Community Health Center, Sikka. CHMK Pharmaceutical Scientific Journal, 3(1), 116-123. Retrieved from http://cyber-

chmk.net/ojs/index.php/farmasi/article/vi ew/603

Plakas, S., Mastrogiannis, D., Mantzorou, M., Adamakidou, T., Fouka, G., Bouziou, A., ... Morisky, D. E. (2016). Validation of the 8Item Morisky Medication Adherence Scale in Chronically III Ambulatory Patients in Rural Greece. Open Journal of Nursing, 06(03), 158-169. https://doi.org/10.4236/ojn.2016.63017

Pusat Data dan Informasi. (2018). Profil Kesehatan tahun 2017. Jakarta: Kementerian Kesehatan RI.

Rantucci, M. . (2007). Komunikasi Apoteker-Pasien (2nd ed.). Jakarta: Buku Kedokteran EGC.

Rosaria Ika Pratiwi, M. P. (2017). Analisis FaktorFaktor Yang Mempengaruhi Kepatuhan Pasien Hipertensi Dalam Penggunaan Obat Di RSUD Kardinah. Jurnal Seminar Nasional IPTEK Terapan (SENIT), 2(1), 204-208.

Sarwono. (2012). Ilmu Kebidanan. Jakarta: Yayasan Bina Pustaka.

Setiadi. (2008). Konsep dan Proses Perawatan Keluarga. Jakarta: Graha IImu.

Shen, Y., Peng, X., Wang, M., Zheng, X., Xu, G., Lü, L., ... Wang, J. (2017). Family memberbased supervision of patients with hypertension: A cluster randomized trial in rural China. Journal of Human Hypertension, 31(1), 29-36. https://doi.org/10.1038/jhh.2016.8

Tan, X., Patel, I., \& Chang, J. (2014). Review of the four item Morisky Medication Adherence 
Scale (MMAS-4) and eight item Morisky Medication Adherence Scale (MMAS-8). INNOVATIONS in Pharmacy, 5(3). https://doi.org/10.24926/iip.v5i3.347

Tania, T., Yunivita, V., \& Afiatin. (2019). Adherence to Antihypertensive Medication in Patients with Hypertension in Indonesia. International Journal of Integrated Health Sciences, $\quad 7(2), \quad 74-80$. https://doi.org/10.15850/ijihs.v7n2.1588

Tumenggung, I. (2013). Hubungan Dukungan Sosial Keluarga dengan Kepatuhan Diet Pasien Hipertensi di Rsud Toto Kabila Kabupaten Bone Bolango . JURNAL HEALTH AND SPORT, 7(01). Retrieved from https://ejurnal.ung.ac.id/index.php/JHS/a rticle/view/1085
Vlasnik, J. J., Aliotta, S. L., \& DeLor, B. (2005). Evidence-based assessment and intervention strategies to increase adherence to prescribed medication plans. Case Manager, 16(2), 55-59. https://doi.org/10.1016/j.casemgr.2005.0 1.010

Zhang, M., Meng, Y., Yang, Y., Liu, Y., Dong, C., Xiao, J., Li, F. (2011). Major inducing factors of hypertensive complications and the interventions required to reduce their prevalence: An epidemiological study of hypertension in a rural population in China. BMC Public Health, 11(1), 301. https://doi.org/10.1186/1471-2458-11301. 